\title{
RESENHA DO LIVRO "O APRENDIZADO DA ORTOGRAFIA"
}

\author{
Alexandra Gomes dos Santos Matos ${ }^{1}$
}

MORAIS, Artur Gomes de, (org). O aprendizado da ORTOGRAFIA. $3^{\text {a }}$ ed. Belo Horizonte: Autêntica, 2002.

O aprendizado da ORTOGRAFIA é uma obra organizada por Artur Gomes de Morais, professor do Departamento de Psicologia e Orientação Educacionais da Universidade Federal de Pernambuco. Ela é composta por uma coletânea de sete artigos que se esmeram em desvelar como o sistema ortográfico é incorporado pelos usuários da escrita. Desse modo, há relevante contribuição no que tange à compreensão dos obstáculos e dos progressos vividos pelas crianças, no processo de aquisição da ortografia; sendo, por isso, uma leitura de suma importância para a formação de professores, sobretudo das séries iniciais. Cada capítulo do livro constitui um artigo, feito por estudiosos da Língua Portuguesa, que convergem na demonstração do papel ativo do sujeito que aprende ortografia.

Logo na apresentação, o organizador da obra tece considerações sobre o processo de aprendizagem da ortografia no texto intitulado Ortografia: este peculiar objeto de conhecimento. Inicia a abordagem demonstrando a diferença entre a orthographia etmológica e a sónica. Para tanto, apropria-se da definição extraída do dicionário, organizado por João Grave e por Coelho Netto nas primeiras décadas do século XX. Ao fazer isso, fomenta, no leitor, o

\footnotetext{
${ }^{\mathrm{I}}$ Mestra e graduada em Letras Vernáculas pela Universidade do Estado da Bahia (UNEB). Teve dissertação de mestrado aprovada com Distinção e Louvor, além de ser advogada, inscrita na Ordem dos Advogados do Brasil (OAB), na seção da Bahia. É professora efetiva de Língua Portuguesa, de Literatura Brasileira e de Direito Constitucional, na condição de Servidora Pública da Secretaria de Educação do Estado da Bahia, bem como de docente do Colégio Santo Antônio de Jesus (Sistema COC de Ensino), além de ser membro do Grupo de Pesquisa Múltiplas Linguagens da UNEB, campus V. É bacharela em Direito, especialista em Estudos Linguísticos e Literários pela Universidade Federal da Bahia, em Direito Educacional pela Faculdade Futura, assim como é pós-graduanda em Educação e Direitos Humanos pela última Instituição de Ensino Superior (IES) mencionada. Já atuou como Parecerista em Revista de Direito da Universidade Federal de Ouro Preto, foi Diretora Executiva e Coordenadora do Curso de Letras da Faculdade Zacarias de Góes, dentre outras atividades relevantes em Direito Educacional.
} 
interesse por curiosidades históricas, além de dar ênfase à ortografia, entendendo-a como produto de um acordo social, uma convenção cujo caráter é normativo e prescritivo. Pondera que nem sempre a ortografia existiu e demonstra que, em se tratando do português, somente na primeira metade do século $\mathrm{XX}$, isso foi possível. $\mathrm{O}$ mesmo, entretanto, não ocorreu com o espanhol e o francês cujos sistemas ortográficos datam de um período que antecede o século XIX. Diante de tamanha diferença, conduz o entendimento de que fatores sociais díspares, a universalização da escolaridade obrigatória, a difusão do livro e o avanço dos meios de comunicação foram determinantes para que não houvesse a postergação da unificação ortográfica nesses países.

Nessa cadência, remonta à Grécia o dilema existente na forma como são fixadas as palavras de uma língua. Pontua que há uma tendência histórica, ao criar a ortografia, de manter uma consonância entre o ideal fonográfico e o princípio ideográfico, questionando o motivo pelo qual não se escreve como se pronuncia e se esbarra na diversidade de falares existentes no Brasil. O Enfatiza que essa diferença não pode ser vista como "acerto" ou “erro", sob pena de ser uma abordagem preconceituosa. Ao mesmo tempo, entende que é uma ilusão acreditar no mito da perfeição alfabética, assim como é forçoso reconhecer a natureza arbitrária do conhecimento ortográfico. Destarte, diferencia-se o aprendizado do sistema de notação alfabética do da norma ortográfica, analisando a tarefa do estudante no exercício de aprender a escrita correta de palavras. Sobre isso, observa Bortoni-Ricardo $(2002, p \cdot 42)^{2}$

Da perspectiva de uma pedagogia culturalmente sensível aos saberes dos alunos, podemos dizer que, diante da realização de uma regra não padrão pelo aluno, a estratégia da professora deve incluir dois componentes: a identificação da diferença e a conscientização da diferença.

Assim, será imperiosa a apropriação tanto das restrições irregulares quanto das regulares, socialmente convencionadas pelo educando. Nessa interface, a ortografia é concebida como sendo a reprodução do modo de escrever autorizado e os possíveis "erros" infantis devem ser compreendidos como oriundos de toda a exploração cognitiva vivenciada

2 BORTONI-RICARDO, Stella Maris. Educação em língua materna: a sociolingüística na sala de aula. 4.ed. São Paulo: Parábola Editorial, 2006. 
durante o processo de aquisição de uma língua. Nesse toar, o texto considera favorável a todo fazer pedagógico, eivado de boas intenções, a classificação de "erros" por "variações" ou "hipóteses", ao se referir às notações infantis. Observa, não obstante, que isso, por si só, não tem o condão de alterar o quadro de ensino e a aprendizagem da ortografia. Por fim, na condição de organizador, assim como de coautor do livro, Arthur Gomes de Morais traça uma-breve visão panorâmica dos textos que sucederão na composição dos capítulos da obra.

Ato contínuo, Lucia Lins Browne Rego, professora de Pós-Graduação em Psicologia da Universidade Federal de Pernambuco, e Lair Levi Buarque, psicóloga do Departamento de Psicologia da mesma Academia, apresentam informações, de alto relevo, consoantes à psicogênese da escrita. Desse modo, salientam a relevância da obra de Ferreiro \& Teberosky (1986), ao demonstrarem o modo como a criança compreende o sistema alfabético de escrita, tendo como marco teórico a abordagem do construtivismo piagetiano, bem como da psicolinguística contemporânea. Contudo, declaram que essa pesquisa ainda não caracterizou categoricamente o progresso da criança após seu ingresso na fase alfabética, destacando que já há consenso doutrinário de que esse momento não mais pode ser visto como estágio.

Rego e Buarque frisam que o sistema de escrita da Língua Portuguesa é o de base alfabética, isto é, as letras representam as unidades sonoras da palavra. Por essa lógica, cada letra deveria representar um som, e cada som, por seu turno, uma letra. Observam, todavia, que tal regularidade é pouco encontrada no idioma em epígrafe, havendo situações em que as diferenças gráficas não correspondem às sonoras, podendo duas ou mais letras concorrerem para representarem um mesmo som. Observam, ainda, que, em tais casos, torna-se imprescindível recorrer a outros níveis de análise, como o morfológico e o sintático, com o fito de prever a grafia adequada. Afirmam que estudos realizados com crianças apontam que o modo como elas aprendem a escrever não tem facilitado a sua compreensão do sistema ortográfico, isto é, entender como a língua funciona. Por isso, propõem discutir os obstáculos enfrentados pelas crianças no exercício de se apropriarem de determinadas regras ortográficas. Para tanto, analisaram os dados oriundos de estudo longitudinal realizado com um grupo de 79 crianças, sendo que 38 delas frequentavam uma escola privada 
e 4I uma instituição de ensino pública, ambas localizadas em um mesmo bairro do Recife. Salientam, em tempo, que todas as observações foram verificadas a partir da realização de ditados de palavras, ou seja, em um dia, ditavam-se palavras reais; no outro, eram ditadas palavras inventadas, inseridas em um contexto de regra ortográfica similar ao das ditadas em dia anterior.

Analisaram a ocorrência do "r" e "rr", do "ou" e "or", assim como a grafia do ditongo /iw/. Nesse percurso, refletem sobre a língua, sugerindo atividades pedagógicas bastante contributivas para o exercício da docência, com o firme propósito de ajudar o aluno na tarefa de se apropriar das regras concernentes ao sistema ortográfico do português. Em uma consonância entre morfologia e ortografia, aduzem que o ditongo "ou" é frequente nos verbos de primeira conjugação, quando flexionados na terceira pessoa do singular do pretérito perfeito do indicativo, ao passo que "or" relaciona-se com os substantivos. No que tange à escrita do ditongo /iw/, trazem a utilização de "iu" como sendo peculiar aos verbos da terceira conjugação, quando flexionados na terceira pessoa do singular do pretérito perfeito do indicativo, ao passo que substantivos e adjetivos são grafados com “il" ou "io". Para investigar a representação dos sons $/ \mathrm{R} / \mathrm{e} / \mathrm{r} /$ intervocálicos, tomaram como parâmetro as palavras que se iniciam em / R/, usualmente grafadas com " $\mathrm{r}$ ", palavras com o som de /R/ entre vogais, no geral, grafadas com "rr", palavras com som de /r/ entre vogais, grafadas com " $r$ ", e palavras com som de /R/ entre consoante e vogal, grafadas com " $r$ ". Por fim, as autoras corroboram os resultados já vistos em estudos anteriores e apontam a necessidade de que o professor realize situações didáticas que favoreçam a aquisição do sistema ortográfico de Língua Portuguesa pela criança por meio do uso gerativo e não simplesmente acumulativo da regra.

A professora do Departamento de Psicologia e Orientação Educacionais da Universidade Federal de Pernambuco, Ana Márcia Luna Monteiro, empreende mais discussões sobre a seara ortográfica em seu artigo intitulado Sebra - ssono - pessado - asado: o uso do 's' sob a ótica daquele que aprende. De pronto, considera que, quando a leitura e a escrita passaram a ser consideradas como fundamentais durante os letramentos do indivíduo, muitos estudos buscaram compreender esse processo. A partir disso, reflete sobre a grafia 
inadequada de alunos com muitos anos de escolarização, o que se configura como uma relação paradoxal, pelo menos do ponto de vista teórico, que se distancia da prática. Diante de tal problemática, busca trazer novos subsídios para que o trabalho com a ortografia, na escola, seja repensado. Para tanto, apresenta alguns resultados advindos de constatações consoantes a leitura e escrita do "s" intervocálico, por crianças da alfabetização à quarta série. Assim, demonstra a necessidade de o professor incentivar o aluno a pensar a língua, sobretudo a partir dos textos que o próprio discente escreve. Orienta o ensino da ortografia sob o viés gerativo, não por meio de regras cumulativas que visem a uma mera internalização.

Gilda Guimarães, professora do Departamento de Métodos e Técnicas de ensino da Universidade Federal de Pernambuco, e Antonio Roazzi, professor do Departamento de Psicologia da mesma Academia, escreveram, por seu turno, o artigo intitulado como A importância do significado na aquisição da escrita ortográfica Iniciam a abordagem elucidando, à luz de Piaget e (192333,1926/734) e Vygotsky5 (1962), a relação de identidade que a criança estabelece entre as palavras e os objetos aos quais se referem. Destarte, pontuam que o primeiro impasse enfrentado pela criança, durante o processo de descoberta da escrita alfabética, consiste na concepção da palavra enquanto uma sequência de sons que independe de seu significado. Uma vez compreendida tal situação, declaram, assim, que a criança ingressa na fase alfabética. Entretanto, observam que ela se depara com outros contextos de realização da língua para os quais essa compreensão não é de todo suficiente. Exemplificam isso por meio do uso das palavras homófonas-heterógrafas e as homófonas-homógrafas. Notam que o significado da palavra pode ainda ser importante como elemento gerador de grafia, no caso das palavras derivadas.

Para avaliar as ocorrências supra, realizaram um estudo com 8o sujeitos, de diferentes graus de escolaridade, $\mathrm{I}^{\underline{a}}, 4^{\underline{a}}$ e $8^{\underline{a}}$ do primeiro grau, bem como $3^{\underline{a}}$ do segundo grau, atual ensino médio. Verificaram a não utilização, de forma consciente, de regras ortográficas para a

\footnotetext{
3 PIAGET, J. Le Language et la pensée chez l'enfant. Neuchâtel: Delachaux et Niestlé, I923.

${ }^{4}$ PIAGET, J. The Child's conception of the world (trad. J. \& A. Tomlinson). Frogmore, St. Albans, Herts: Paladin, $1926 / 73$.

${ }^{5}$ VYGOTSKY, L.S. Thought and language. Cambridge, M. A.: MIT Press, 1962.
} 
representação de radicais cujo significado é semelhante. Ponderam que a prática docente deveria favorecer a aprendizagem por meio de radicais semânticos iguais, por isso escritos da mesma forma - uma vez que essa prática minimiza a necessidade de memorização da grafia convencional de Língua Portuguesa e, consequentemente, diminui a incidência de erros ortográficos. Consideram que, de igual modo, o resultado não foi exitoso quando os alunos se defrontaram com palavras homófonas-heterógrafas e homófonas-homógrafas, o que demonstra não ter sido o significado um fator relevante na diferenciação da escrita. Desse modo, analisam a pouca contribuição que a escola tem dado para que os indivíduos produzam uma grafia correta, separando o que pode ser generalizado daquilo que é particular. Assim, consideram que, na busca pela ortografia correta, os alunos apresentam diferentes concepções morfossintáticas e expressam a sua compreensão da relação significado e ortografia, enfatizando a ideia de que a escola precisa trabalhar com a semântica como forma de orientar a grafia correta. Nessa perspectiva, concebe a escola como espaço de reflexão e conscientização linguística.

O professor Artur Gomes de Morais, já devidamente apresentado, além de ser o organizador da obra e autor de sua apresentação, escreveu o artigo intitulado Por que gozado não se escreve com u no final? Os conhecimentos explícitos verbais da criança sobre a ortografia. Ao realizar a sua pesquisa, o autor convidou crianças para a tarefa de escrever errado de propósito. A intenção dele era examinar a relação existente entre o rendimento ortográfico delas e o que são capazes de verbalizar sobre essas regras ortográficas. Embora tenha feito esse estudo tanto com crianças espanholas quanto com brasileiras, deteve a sua análise, no trabalho em apreço, às últimas. Constatou que as crianças oriundas de escola pública tinham desempenho ortográfico aquém quando confrontadas com seus pares que estudavam na rede privada de ensino. Diante disso, verificou, ainda, que os alunos com melhor desempenho produziam mais erros intencionais que aqueles com pior desempenho, o que comprova a hipótese, que o autor já tinha levantado, de que para transgredir intencionalmente, é preciso ter mais conhecimento a um nível explícito. Por fim, entende que, para se colocar em prática, um ensino voltado à explicação dos conhecimentos sobre a ortografia, é necessário que o docente substitua o treino pela reflexão ortográfica. 
Telma Ferraz Leal, professora do Departamento de Métodos e Técnicas de Ensino da Universidade Federal de Pernambuco, e Antonio Roazi, professor do Departamento de Psicologia da mesma Academia, escreveram o artigo A criança pensa... e aprende ortografia. Neste, os professores discutem o caráter criativo e gerativo do exercício da aprendizagem ortográfica. Assim sendo, ressaltam o papel da reflexão na construção dos conhecimentos ortográficos. Observam a relevância dos estudos de Ferreiro e Teberosky ${ }^{6}$ (1985). Estes afirmam que, quando a criança passa do estágio pré-silábico para o silábico e do silábico para o alfabético, ela estabelece relações entre a escrita e a fala. Contudo, ao ingressar no nível alfabético, a criança somente continuará a evoluir se ela perceber a dissociação da escrita com a sua oralização. O professor contribuirá para esse avanço se compreender a aprendizagem da ortografia de modo reflexivo e não um produto de mero treino de palavras.

Destacam que, embora alguns autores, como Stanovich e West ${ }^{7}$ (1989), apontem que as pessoas de maior contato com a língua escrita apresentam melhor desempenho em tarefas ortográficas, isso, por si só, não tem o condão de lograr o êxito esperado. Afirmam a existência de fatores diversos que devem ser somados a esses, como a frequência de uso das palavras, e, nos termos de Nunes e Bryant (2004), as relações da consciência metalinguística com a ortografia. Nesse toar, concebem as restrições ortográficas como sendo operadas, dentre outros motivos, a partir das regras sintático-morfológicas e fonológicas da Língua Portuguesa. Mencionam a realização de um estudo no qual analisam possíveis erros ortográficos, como os que geralmente ocorrem em palavras terminadas em o/u e i/e, observando a lógica desses erros nas falas das crianças, bem como a respectiva regularidade, presente na escrita, para justificar a grafia convencional. Assim, a escolha de uma letra ou de outra decorre da análise da tonicidade da palavra. Por fim, define o erro da escrita como um indício pelo qual o professor vai compreender como ocorre o aprendizado da ortografia, não devendo ser visto como mera manifestação de um não saber.

\footnotetext{
${ }^{6}$ FERREIRO, E. \& Teberosky A. A psicogênese da língua escrita. Porto Alegre: Artes Médicas, 1985.

7 STANOVICH, K. E. \& West, R. F. Exposure to print and orthographic processing. Reading researche quartely, XXIV, 4, I989, p. 402-33.
} 
Cinara Santana da Silva, professora da Escola Matias de Albuquerque da rede estadual de ensino de Pernambuco, e Ana Carolina Perrusi Brandão, professora do Departamento de Métodos e Técnicas de Ensino da Universidade Federal de Pernambuco, redigiram o artigo Reflexões sobre o ensino e a aprendizagem da pontuação. Justificam a eleição da pontuação por ser tema com função essencial na leitura e produção de textos, um dos principais eixos do ensino de Língua Portuguesa, sobretudo nas séries iniciais. Afirmam que, segundo Carvalho e Baraldi (1995) ${ }^{8}$, na história da escrita, a pontuação teve uma evolução tardia. De igual modo, a criança passa por diversas fases até perceber a necessidade de pontuar o texto. Advertem sobre a relevância do estudo em tela por oportunizar a viabilização de estratégias para tornar a pontuação observável pelas crianças. Ponderam o fracasso escolar no que concerne ao assunto em epígrafe, por tratar a pontuação de forma inadequada, isto é, como recurso que auxilia a fala. Assim sendo, os sinais indicam o tamanho das pausas a serem dadas na leitura em voz alta. Refletem, entretanto, sobre a necessidade de dar relevo ao lugar natural da pontuação que é a produção textual.

Considerando os aspectos supra, propõem atividades didáticas que deveriam ser desenvolvidas numa sala de $3^{\underline{a}}$ série de uma escola pública do Recife, com 26 alunos (entre 8 e I2 anos), dos quais 5 eram novatos e II deles já haviam sido reprovados pelo menos uma vez. Explicita os resultados positivos que obtiveram com as ações pedagógicas realizadas. Desse modo, contribui, de forma significativa, com a formação de professores, sobretudo os de séries iniciais, por oferecer referências concretas sobre um ensino de um tópico relevante na tarefa de formar usuários da língua competentes na tarefa de se comunicar. Enfatizam todo esse estudo em torno da necessidade de mudar a maneira como é ensinada a ortografia, demonstrando como tem fracassado a opção não voltada para o exercício da consciência linguística pelo educando. Verificam que este é um sujeito ativo no processo de aprendizagem, sendo uma obra voltada, sobretudo, para os professores de séries iniciais.

A excelência do livro $O$ aprendizado da ortografia reside justamente neste aspecto: traz abordagens atuais e reflexivas sobre o aprendizado da ortografia, o que favorece o exercício

\footnotetext{
${ }^{8}$ CARVAlHO, C. S. e BARALDI, M. G. da: Escrita, gramática, ortografia. São Paulo: Ática, v.I, 1995.
} 
da prática docente, na tarefa de desenvolver a competência comunicativa dos alunos. Assim sendo, é um livro que se torna imprescindível para os estudiosos da língua materna e todos aqueles que exercem ou pretendem praticar o ofício do ensino em sala de aula. 